\title{
Differential photosynthetic responses of marine planktonic and benthic diatoms to ultraviolet radiation under various temperature regimes
}

\author{
Yaping $\mathrm{Wu}^{1}$, Furong Yue ${ }^{2}$, Juntian $\mathrm{Xu}^{2,3}$, and John Beardall ${ }^{4}$ \\ ${ }^{1}$ College of Oceanography, Hohai University, Nanjing, 210098, China \\ ${ }^{2}$ College of Marine Life and Fisheries, Huaihai Institute of Technology, Lianyungang, 222005, China \\ ${ }^{3}$ Co-Innovation Center of Jiangsu Marine Bio-industry Technology, Lianyungang, 222005, China \\ ${ }^{4}$ School of Biological Sciences, Monash University, Clayton, Victoria, 3800, Australia
}

Correspondence to: Juntian Xu (jtxu@hhit.edu.cn)

Received: 6 March 2017 - Discussion started: 14 March 2017

Revised: 8 August 2017 - Accepted: 10 October 2017 - Published: 14 November 2017

\begin{abstract}
We studied the photophysiological responses to ultraviolet radiation (UVR) of two diatoms, isolated from different environmental niches. Both species showed the highest sensitivity to UV radiation under relatively low temperature, while they were less inhibited under moderately increased temperature. Under the highest temperature applied in this study, the benthic diatom Nitzschia sp. showed minimal sensitivity to UV radiation, while inhibition of the planktonic species, Skeletonema sp., increased further compared with that at the growth temperature. These photochemical responses were linked to values for the repair and damage processes within the cell; higher damage rates and lower repair rates were observed for Skeletonema sp. under suboptimal temperature, while for Nitzschia sp., repair rates increased and damage rates were stable within the applied temperature range. Our results suggested that the response of the microalgae to UV radiation correlated with their niche environments, the periodic exposure to extreme temperatures promoting the resistance of the benthic species to the combination of high temperature and UV radiation.
\end{abstract}

\section{Introduction}

As the most abundant group of microalgae, and one that plays an important role in marine ecosystem function and biogeochemical cycles, diatoms are traditionally divided into centric and pennate species on the basis of their valve symme- try (Round et al., 1990). Centric diatoms are usually, though not invariably, planktonic; pennate species are benthic and are often found living in different niches (Irwin et al., 2012; Keithan et al., 1988). The distribution of centric diatoms is more widespread, with records for the open ocean as well as coastal water, and they maintain their position in the upper mixing layer by maintaining buoyancy with elaborated spines or excretion of heavy ions (Lavoie et al., 2016; Villareal, 1988). In contrast, pennate diatoms are often found in the intertidal zone (Stevenson, 1983). Therefore, the two groups of diatoms are likely to have evolved different strategies to cope with their niche environments (Barnett et al., 2015; Lavaud et al., 2016, 2007).

Temperature affects almost all biochemical reactions in living cells, and it is one of the most important factors that determines the biogeography, as well as the temporal variation of phytoplankton (Levasseur et al., 1984). Under global change scenarios, increases in sea surface temperature would re-structure the phytoplankton assemblages in the future ocean (Thomas et al., 2012). At small spatial scales (e.g., the coastal zone) diurnal cycle of tides or meteorological events could expose benthic diatoms to extreme environments, including high photosynthetically active radiation (PAR) and ultraviolet (UV) radiation exposure as well as larger variations in temperature than found for planktonic species. Hence organisms in such exposed areas should potentially possess highly efficient mechanisms to adapt to such an environment (Souffreau et al., 2010; Weisse et al., 2016). 
In the intertidal zone, UV radiation (UVR) is another driving force. UVR is a component of the solar spectrum, along with PAR, and has wide-reaching effects on organisms, especially photoautotrophs due to their demands for light energy (Williamson et al., 2014). The penetration of effective UVR in coastal waters is mainly dependent on the properties of the seawater (Tedetti and Sempere, 2006). Previous studies have found that UVR significantly inhibited carbon fixation by phytoplankton in the surface layer, with less inhibition or even stimulation in deep water due to low UVR and limiting levels of PAR (Gao et al., 2007). Detrimental effects, however, varied seasonally, with less inhibition observed for planktonic assemblages during summer, though UVR was the highest. This may be attributable to the higher water temperature, which facilitated enzyme-catalyzed repair processes within the cell (Wu et al., 2010). There are few documented studies on benthic species, which actually are potentially more resistant to UVR as they are periodically exposed to high solar radiation during low tide (Barnett et al., 2015).

Photosystem II (PSII) initiates the first step of photosynthesis, converting photons to electrons efficiently, but this complex is very sensitive to light (Campbell and Tyystjarvi, 2012). The subunits of PSII are broken down under UVR or high PAR while repaired by insertion of de novo synthesized protein (Aro et al., 1993); the repair process eventually reaches a dynamic balance with damage (Heraud and Beardall, 2000). However, these two processes are independent of each other. The photochemical damage is mainly determined by the intensity and spectrum of light (Heraud and Beardall, 2000) and is temperature insensitive, while the repair process is driven by a series of enzyme-catalyzed reactions and is thus potentially sensitive to temperature changes (Melis, 1999). Previous studies revealed that high temperature alleviated UV inhibition of PSII in green algae (Wong et al., 2015), while it interactively decreased photosynthetic activity in microphytobenthos under excessive PAR conditions (Laviale et al., 2015).

Considering the importance of diatoms to coastal primary productivity (Carstensen et al., 2015), their responses to environmental factors are of considerable interest (Häder et al., 2011). However, the niches in which planktonic and benthic diatom species exist have quite different physical and chemical characteristics (Souffreau et al., 2010). In this study, we used two freshly isolated species to test the hypothesis that benthic diatoms have a stronger ability to adapt to potentially stressful solar UV radiation under high-temperature regimes.

\section{Materials and methods}

\subsection{Species and culture conditions}

We collected samples from offshore water and intertidal sediments in the coastal area of the Yellow Sea. These were re-suspended in seawater and enriched with Aquil medium and incubated in a growth chamber for 3 days (Morel et al., 1979). Then a sub-sample was examined under a microscope, and single cells were picked up with a micropipette. Skeletonema sp. and Nitzschia sp. were chosen for the present study and were maintained in Aquil medium in a growth chamber at $15^{\circ} \mathrm{C}$. Prior to the experiment, both species were inoculated into enriched seawater (Aquil medium) and cultured semi-continuously in $500 \mathrm{~mL}$ polycarbonate bottles, illuminated with cool fluorescent tubes at a photon flux density of $\sim 200 \mu \mathrm{mol} \mathrm{m}^{-2} \mathrm{~s}^{-1}$, with a $12: 12$ light / dark cycle. Temperature was set at 15,20 , or $25^{\circ} \mathrm{C}$, with variation less than $0.5^{\circ} \mathrm{C}$, and cultures were diluted every day with fresh medium. Bottles (triplicates for each temperature) were manually shaken $2-3$ times during the light period and randomly distributed in the growth chamber.

Specific growth rate was estimated from the changes of dark adapted chlorophyll fluorescence (see below) and calculated as $\mu=\left(\operatorname{Ln} F_{2}-\operatorname{Ln} F_{1}\right) /\left(D_{2}-D_{1}\right)$, where $F_{1}$ and $F_{2}$ represent the steady-state fluorescence intensity at day 1 and day 2 , respectively.

\subsection{Determination of the absorption spectra of pigments}

A total of $50 \mathrm{~mL}$ of culture was filtered onto a $\mathrm{GF} / \mathrm{F}$ filter, and extracted in $5 \mathrm{~mL}$ absolute methanol for $2 \mathrm{~h}$ at room temperature in a $10 \mathrm{~mL}$ centrifuging tube, then centrifuged at $4000 \mathrm{rpm}$ for $15 \mathrm{~min}$ (TDZ4-WS, Luxiang Inc.). The supernatant was scanned with a spectrophotometer (Lambda 35, PerkinElmer) in the range of $280-750 \mathrm{~nm}$.

\subsection{Experimental setup}

The experiments were performed under a customized solar simulator with a $1000 \mathrm{~W}$ xenon arc lamp as the light source. The incident irradiances of UV-B light $(280-315 \mathrm{~nm})$, UV-A (315-400 nm), and PAR (400-700 nm) were measured using a broadband radiometer (SOLAR-2UV, TINEL Inc., http:// www.tinel.cn).

After 5-day acclimation under the target temperature, samples of both species in the exponential phase were harvested during the middle of the light period and directly transferred to quartz tubes $(35 \mathrm{~mL})$ at a density of less than $20 \mu \mathrm{g} \mathrm{chl} a \mathrm{~L}^{-1}$, dark-adapted for $15 \mathrm{~min}$, and treated by addition of Milli-Q water (as a control) or lincomycin (final concentration, $0.5 \mathrm{mg} \mathrm{mL}^{-1}$ ); the latter inhibits protein synthesis and was used to get a better determination of damage rate in the absence of repair. The tubes were then placed into a water bath one after another at $1 \mathrm{~min}$ intervals while covered with cut-off filters (ZJB280, ZJB400) that block radiation below 280 or $400 \mathrm{~nm}$, respectively (the filters' properties were checked by scanning in the wavelength range of 250-750 nm against air as a blank; see Fig. S1 in the Supplement), to create PAR + UV-A + UV-B (PAB) and 

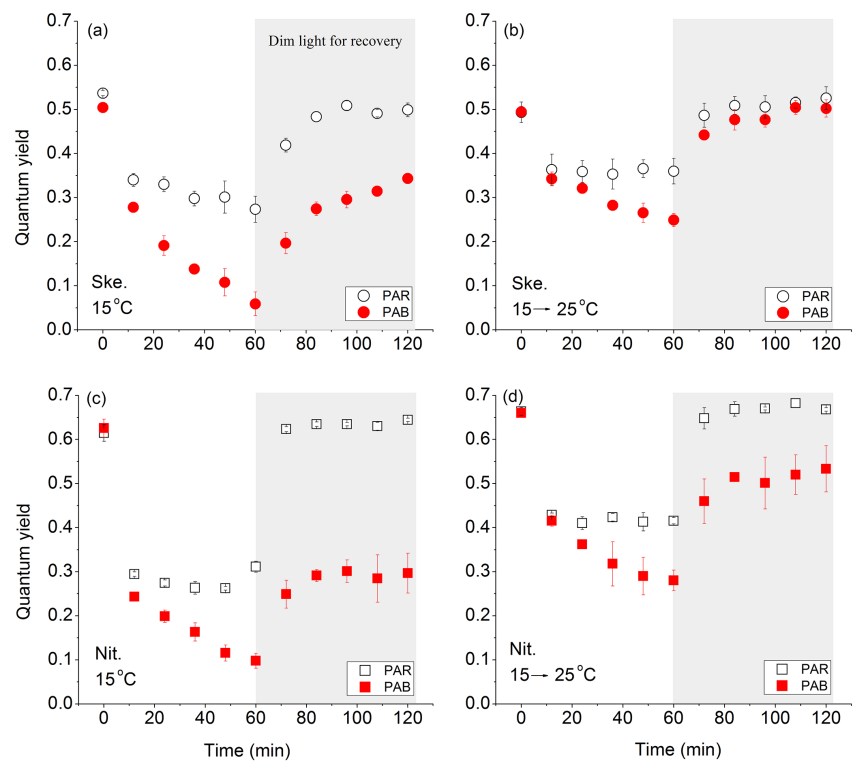

Figure 1. The quantum yields of $15^{\circ} \mathrm{C}$ grown Skeletonema sp. and Nitzschia sp. under PAR or PAR + UVR (PAB) for $1 \mathrm{~h}$ exposure and subsequent recovery under dim light (gray area) for $1 \mathrm{~h}$, which were incubated and measured at $15^{\circ} \mathrm{C}$ (a Skeletonema sp., c Nitzschia sp.) or $25^{\circ} \mathrm{C}$ (b Skeletonema sp., d Nitzschia sp.). Vertical lines represent $\mathrm{SD}, n=3$.

PAR treatments respectively. The light levels applied were $\mathrm{PAR}=440 \mu \mathrm{mol}$ photons $\mathrm{m}^{-2} \mathrm{~s}^{-1}$ and $\mathrm{UVR}=41.6 \mathrm{~W} \mathrm{~m}^{-2}$, while temperature was controlled with a cooling system (CTP3000, Eyela) and was set as the incubation level (termed "acclimated") or the incubation temperature $+10^{\circ} \mathrm{C}$ (termed "short-term"), the latter mimicking a moderate increase in temperature in the intertidal zone during a low-tide period. After the light exposure, samples were moved into a water bath at the same temperature as light exposure, but under dim light $\left(\sim 30 \mu \mathrm{mol}\right.$ photons $\left.\mathrm{m}^{-2} \mathrm{~s}^{-1}\right)$ for recovery, effective quantum yields were then measured at $12 \mathrm{~min}$ intervals. The detailed experimental design can be found in Fig. S2.

\subsection{Chlorophyll fluorescence measurements}

A total of 12 tubes $(2$ species and 2 radiation treatments for each temperature level) were dark-adapted for $15 \mathrm{~min}$. Then each tube was moved into a water bath one by one at $1 \mathrm{~min}$ intervals for light exposure, and $2 \mathrm{~mL}$ sub-samples were taken to measure the initial chlorophyll fluorescence with an AquaPen fluorometer (AP-C 100, PSI). During the subsequent light exposure, sub-samples were withdrawn every $12 \mathrm{~min}$ from the quartz tubes for fluorescence measurement; this procedure ensured that every sample was exposed to radiation for exactly the same time. After five rounds of measurements $(60 \mathrm{~min})$, samples that were without lincomycin were transferred into the low-light condition under the same temperature for recovery, and chlorophyll fluorescence was measured as above for $60 \mathrm{~min}$.
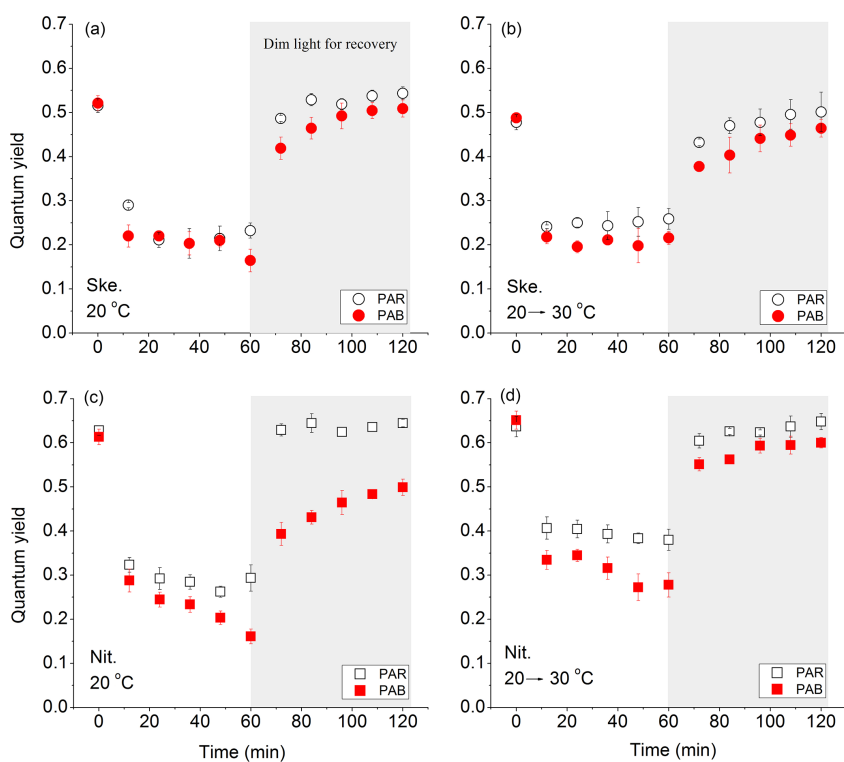

Figure 2. The quantum yields of $20^{\circ} \mathrm{C}$ grown Skeletonema sp. and Nitzschia sp. under PAR or PAB for $1 \mathrm{~h}$ exposure and subsequent recovery under dim light (gray area) for $1 \mathrm{~h}$, which were incubated and measured at $20^{\circ} \mathrm{C}$ (a Skeletonema sp., c Nitzschia sp.) or $30^{\circ} \mathrm{C}$ (b Skeletonema sp., d Nitzschia sp.). Vertical lines represent SD, $n=3$.

\subsection{Data analysis}

Effective quantum yields were measured after $20 \mathrm{~s}$ of dark period (operational time between sampling and measuring) with the AquaPen and calculated according to the following equations:

effective quantum yield $=\left(\mathrm{F}_{\mathrm{m}}^{\prime}-\mathrm{F}_{o}^{\prime}\right) / \mathrm{F}_{\mathrm{m}}^{\prime}$,

where $\mathrm{F}_{\mathrm{m}}^{\prime}$ is the effective maximal fluorescence, and $\mathrm{F}_{o}^{\prime}$ is the minimal fluorescence in the presence of nonphotochemical quenching which persists after highlight exposure.

The relative UV inhibition of effective quantum yield was estimated according to the following equation:

relative UV inhibition $(\%)=\left(P_{\mathrm{P}}-P_{\mathrm{PAB}}\right) / P_{\mathrm{P}} \times 100$,

where $P_{\mathrm{P}}$ and $P_{\mathrm{PAB}}$ represent the effective quantum yield under PAR and PAB treatments, respectively. Relative UV inhibition was calculated when $P_{\mathrm{P}}$ and $P_{\mathrm{PAB}}$ were significantly different.

The rates of UVR-induced damage to PSII $\left(k, \min ^{-1}\right)$ were calculated from lincomycin-treated samples assuming repair $(r)$ under these conditions was zero. Repair rates $(r$, $\min ^{-1}$ ) were calculated using non-lincomycin-treated samples with the fixed $k$ values obtained from the parallel experiments with lincomycin. Both calculations were made according to the Kok equation (Heraud and Beardall, 2000):

$\frac{\mathrm{P}_{t}}{\mathrm{P}_{0}}=\frac{r}{k+r}+\frac{k}{k+r} e^{-(k+r) t}$, 

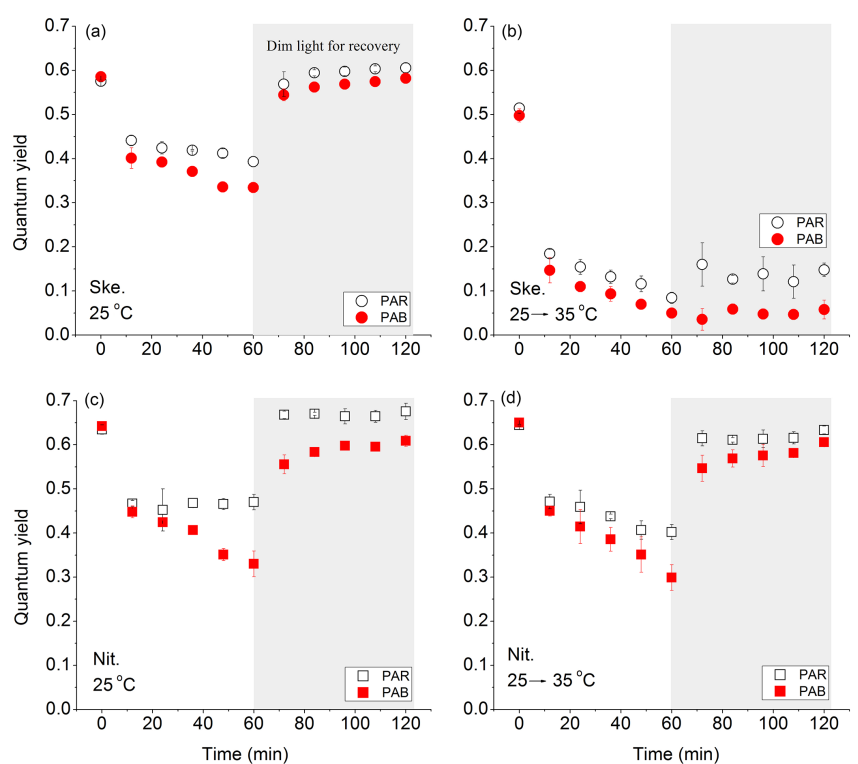

Figure 3. The quantum yields of $25^{\circ} \mathrm{C}$ grown Skeletonema sp. and Nitzschia sp. under PAR or PAB for $1 \mathrm{~h}$ exposure and subsequent recovery under dim light (gray area) for $1 \mathrm{~h}$, which were incubated and measured at $25^{\circ} \mathrm{C}$ (a Skeletonema sp., c Nitzschia sp.) or $35^{\circ} \mathrm{C}$ (b Skeletonema sp., d Nitzschia sp.). Vertical lines represent SD, $n=3$.

where $P_{0}$ and $P_{t}$ represent the effective quantum yield at time zero and $t$ (minutes), respectively.

The recovery rates under dim light were calculated with a simple exponential rise equation (Heraud and Beardall, 2000):

$y=y_{0}+c\left(1-e^{-\alpha t}\right)$,

where $y$ represents the effective quantum yield at time $t$ (minutes) during the dim light incubation, $\alpha$ was the recovery rate, while $y_{0}$ and $c$ are constants.

Statistical differences for the kinetics of changes in effective quantum yield among treatments were analyzed with repeated measures analysis of variance (RM-ANOVA). The differences of relative UV inhibition and rate constants among treatments were analyzed by one-way ANOVA; a confidence interval of $95 \%$ was set for all tests. For the calculation of the ratio of $r: k$ and the relative UV inhibition $(\%)$, propagation errors were taken into account to estimate variance.

\section{Results}

The initial photochemical quantum yield of Skeletonema sp. grown at $15^{\circ} \mathrm{C}$ was around 0.50 during light exposure (incubated under $15^{\circ} \mathrm{C}$ ) but decreased gradually toward the end of the radiation treatments, with lower values under PAB than under the PAR condition ( $p<0.001, F=30.1$; Fig. 1a, Table S1 in the Supplement). During the dim light exposure
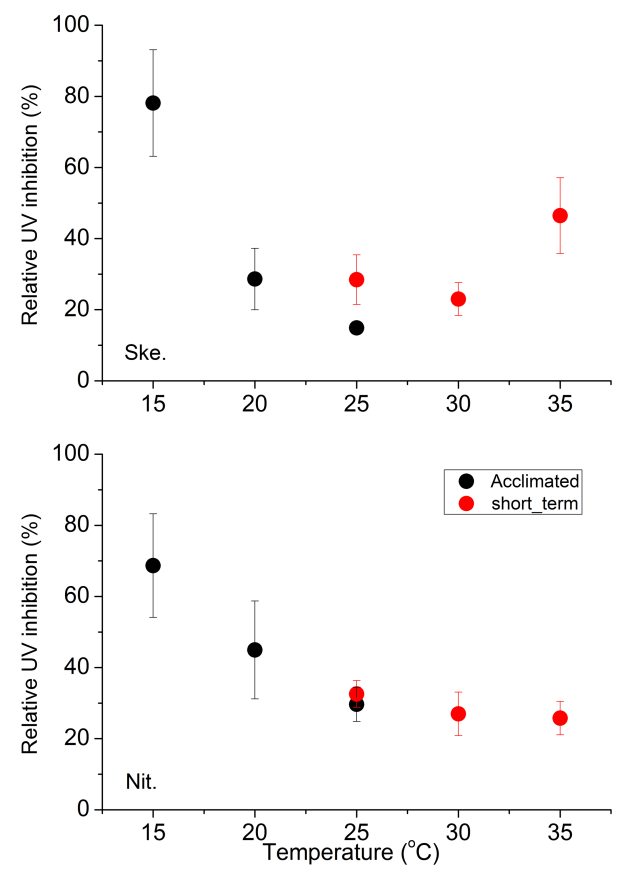

Figure 4. The relative UV inhibition on the photosystem II of Skeletonema sp. (a) and Nitzschia sp. (b) under grown or short-term elevated temperature. Vertical lines represent variance.

period, the quantum yield recovered to its initial value within 24 min under PAR treatment, while PAB-treated cells only recovered partially to $\sim 70 \%$ by the end of the dim light incubation (Fig. 1a). For $15^{\circ} \mathrm{C}$ grown cells that were incubated under $25^{\circ} \mathrm{C}$, the general patterns were similar to those incubated under $15^{\circ} \mathrm{C}$; the differences between the PAR and PAB treatments were smaller but still significant $(p<0.001$, $F=9.8$; Fig. 1b, Table S1). Under dim light, the quantum yield of cells under both radiation treatments recovered to near initial values (Fig. 1b). For $15^{\circ} \mathrm{C}$ grown Nitzschia sp. that was measured at $15^{\circ} \mathrm{C}$, the pattern of decrease in effective quantum yield was similar to that of Skeletonema sp., with lower values under PAB ( $p<0.001, F=38.8$; Fig. 1c, Table S1). In addition, PAB-exposed Nitzschia sp. could only recover to $\sim 50 \%$ of the initial value under dim light (Fig. 1c). However, when $15^{\circ} \mathrm{C}$ grown Nitzschia sp. were incubated at $25^{\circ} \mathrm{C}$ for light exposure, both PAR- and PABtreated cells had higher quantum yields, and PAB-exposed cells recovered to $75 \%$ of the initial value when subsequently incubated under dim light (Fig. 1d). The increase of temperature $\left(15\right.$ to $\left.25^{\circ} \mathrm{C}\right)$ and $\mathrm{UV}$ radiation also showed interactive effects for both Skeletonema sp. ( $p=0.022, F=2.98)$ and Nitzschia sp. ( $p=0.046, F=2.5$; Table S2).

The $20^{\circ} \mathrm{C}$ grown Skeletonema sp. showed significant UV inhibition at incubation temperatures of $20^{\circ} \mathrm{C}(p<0.001$, $F=8.9)$ and $30^{\circ} \mathrm{C}(p=0.033, F=3.1)$ and recovered more quickly under dim light, especially for the PABtreated cells, compared with samples under $15^{\circ} \mathrm{C}$ (Fig. 2a, 

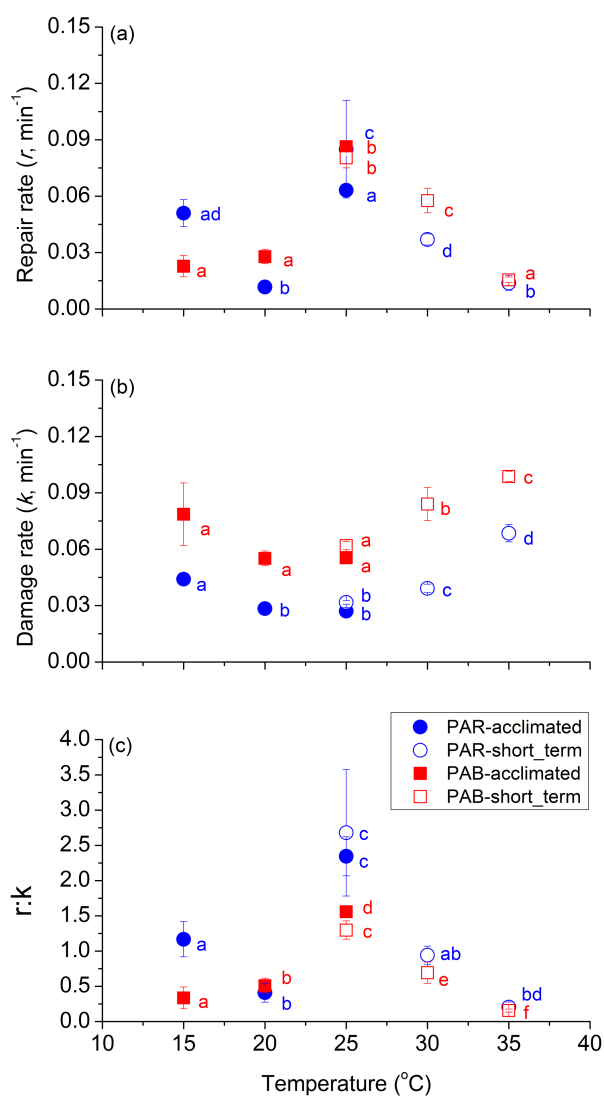

Figure 5. The repair rate (a) and damage rate (b) of photosystem II in Skeletonema sp. during PAR or PAB exposure under grown temperature (acclimated) or short-term elevated temperature (short_term), and the ratio of repair to damage rate (c). Vertical lines in panel (a) and (b) represent $\mathrm{SD}, n=3$, while vertical lines in panel (c) represent variance. Data points with different lowercase letters (blue for PAR treatment, and red for PAB treatment) indicate significant differences among temperature treatments.

b, Table S1). For Nitzschia sp. that were grown at $20^{\circ} \mathrm{C}$, cells showed moderate UV inhibition during radiation exposure $(p<0.001, F=10.1)$, and the quantum yield under PAB treatment only recovered to $\sim 80 \%$ at the end of the dim light incubation at $20^{\circ} \mathrm{C}$, while quantum yield recovered to the initial value in cells measured under $30^{\circ} \mathrm{C}$ (Fig. 2c, d, Table S1). Interactive effects of temperature increase $\left(20\right.$ to $\left.30^{\circ} \mathrm{C}\right)$ and UV radiation were observed for both Skeletonema sp. $(p<0.01, F=4.35)$ and Nitzschia sp. $(p=0.015, F=3.26$; Table $\mathrm{S} 2)$.

Skeletonema sp. that was grown and measured at $25^{\circ} \mathrm{C}$ showed a similar pattern to that grown under $20^{\circ} \mathrm{C}$ during both radiation exposure and subsequent dim light (Fig. 3a). However, quantum yields decreased significantly once cells were moved into $35^{\circ} \mathrm{C}$, with much lower values observed under the PAB and PAR treatments $(p<0.001)$ than under $25^{\circ} \mathrm{C}$. However, there was no significant difference between $\mathrm{PAB}$ and PAR treatments under $35^{\circ} \mathrm{C}(p=0.60, F=0.74$;
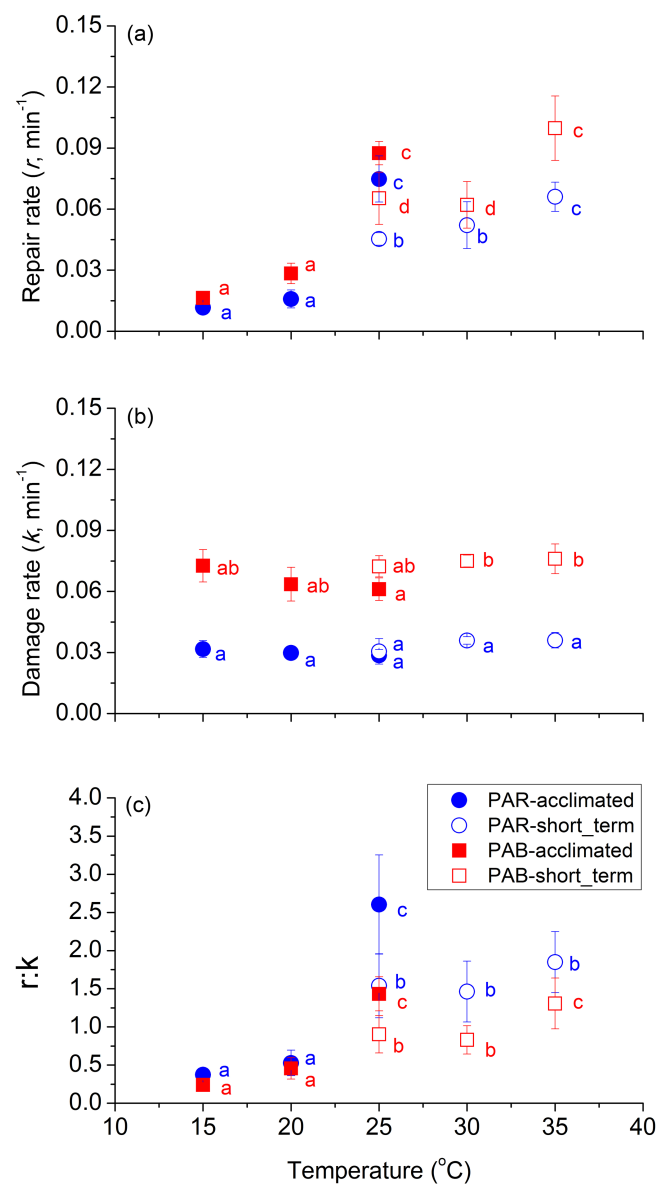

Figure 6. The repair rate (a) and damage rate (b) of photosystem II in Nitzschia sp. during PAR or PAB exposure under grown temperature (acclimated) or short-term elevated temperature (short_term), and the ratio of repair to damage rate (c). Vertical lines in panel (a) and (b) represent $\mathrm{SD}, n=3$, while vertical lines in panel (c) represent variance. Data points with different lowercase letters (blue for PAR treatment, and red for PAB treatment) indicate significant differences among temperature treatments.

Table S1). During the dim light period, Skeletonema sp. only recovered to $\sim 30 \%$ for the PAR treatment, while there was no recovery after the PAB treatment (Fig. 3b). For Nitzschia sp. measured under 25 or $35^{\circ} \mathrm{C}$, both treatments showed a similar response, with lower values under PAB than under PAR during the radiation exposure $(p<0.001$ and $F=13.3$ at $25^{\circ} \mathrm{C}, p<0.01$ and $F=5.4$ at $35^{\circ} \mathrm{C}$; Table S1), while cells could recover to near initial values at the end of the dim light incubation (Fig. 3c, d). An interactive effect of temperature increase $\left(25-35^{\circ} \mathrm{C}\right)$ and UV radiation was only observed for Skeletonema sp. $(p=0.049, F=2.46$; Table S2).

In the presence of lincomycin, changes in effective quantum yield showed a decreasing pattern with exposure time for most of the treatments (Figs. S3-5), but with much greater amplitude compared with non-lincomycin-treated samples. The relative UV inhibition at the end of radiation exposure 

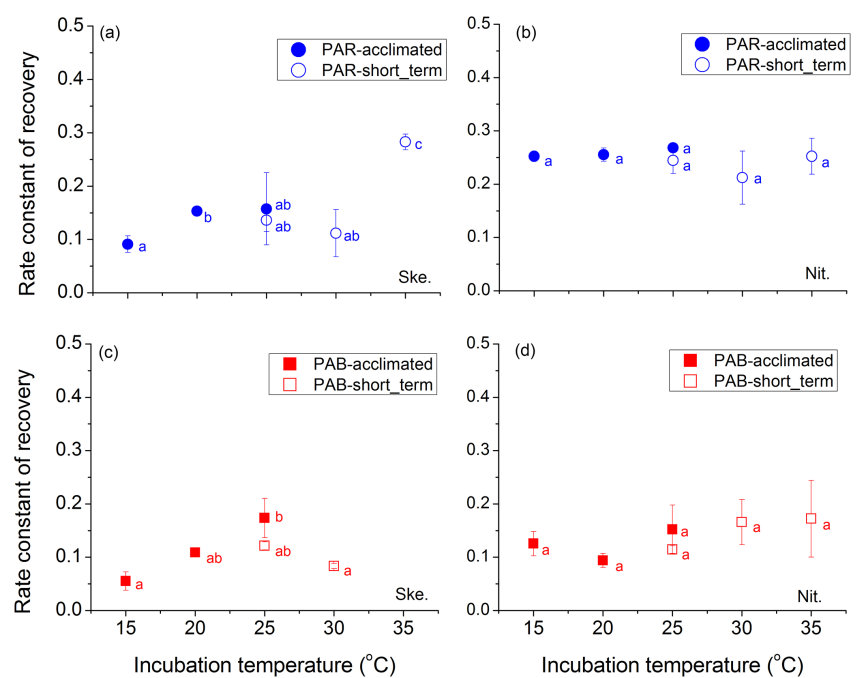

Figure 7. The rate constants for recovery of PAR-exposed Skeletonema sp. (a) and Nitzschia sp. (b), and rate constants for recovery of PAB-exposed Skeletonema sp. (c) and Nitzschia sp. (d) Under dim light, samples were incubated under grown temperature (acclimated) or short-term elevated temperature (short_term). Vertical lines represent $\mathrm{SD}, n=3$. Data points with different lowercase letters (blue for PAR treatment, and red for PAB treatment) indicate significant differences among temperature treatments.

is shown in Fig. 4. Both species showed the greatest sensitivities under $15^{\circ} \mathrm{C}$, with $\sim 80$ and $\sim 70 \%$ relative UV inhibition of photochemical quantum yield for Skeletonema sp. and Nitzschia sp., respectively. In the range of acclimated temperatures, relative UV inhibition decreased with increase of temperature for both species. In the short-term incubations with a $10^{\circ} \mathrm{C}$ increase, UV inhibition of Skeletonema sp. was comparable at 25 and $30^{\circ} \mathrm{C}$, but increased significantly to $\sim 50 \%$ at $35^{\circ} \mathrm{C}(p<0.01)$. For Nitzschia sp., relative UV inhibition was around $25 \%$ in the temperature range of $25-35^{\circ} \mathrm{C}$ during the short-term incubations.

During radiation exposure, the repair rates for PSII in Skeletonema sp. varied across the different temperatures, with highest values observed at $25^{\circ} \mathrm{C}$, and lowest values at $35^{\circ} \mathrm{C}$ for both radiation treatments (Fig. 5a). The damage rates gradually decreased from 15 to $25^{\circ} \mathrm{C}$, then increased significantly toward $35^{\circ} \mathrm{C}$ (Fig. $5 b ; p<0.001$ ). The ratio of repair rate to damage rate $(r: k)$ showed a unimodal pattern with peak values at $25^{\circ} \mathrm{C}$, and with lowest values under 15 or $35^{\circ} \mathrm{C}$, especially for the PAB treatment (Fig. $5 \mathrm{c}$ ).

The repair rate during light exposure for Nitzschia sp. increased significantly in the temperature range of 15 to $25^{\circ} \mathrm{C}(p<0.001)$ while remaining relatively stable from 25 to $35^{\circ} \mathrm{C}$ (Fig. 6a). The damage rates were quite stable for all temperatures tested, whether cells were acclimated or exposed to short-term elevation of temperature, with mean values around 0.075 for PAB and 0.032 for PAR treatment (Fig. 6b). The $r: k$ ratio increased with temperature in the range of $15-25^{\circ} \mathrm{C}$, reaching relatively stable values of around 1.50 for PAR, and around 1.0 for the PAB treatment (Fig. 6c).

Under dim light, the rate constants for recovery of PARexposed Skeletonema sp. were around $0.10-0.15 \mathrm{~min}^{-1}$ in the range of $15-30^{\circ} \mathrm{C}$, but increased significantly to around 0.30 at $35^{\circ} \mathrm{C}(p<0.01$; Fig. 7a). The rate constant for recovery of PAR-exposed Nitzschia sp. was relatively stable, around $0.25 \mathrm{~min}^{-1}$, across the range of applied temperature (Fig. 7b). The rate constant for recovery of PAB-exposed Skeletonema sp. showed an increasing pattern from 0.05 to $0.17 \mathrm{~min}^{-1}$ in the range of $15-25^{\circ} \mathrm{C}$ but decreased significantly at $30^{\circ} \mathrm{C}(p<0.05)$; at $35^{\circ} \mathrm{C}$ values were unable to be estimated due to poor fitting of data points (Fig. 7c). No consistent trend was found for the rate constant for recovery of PAB-exposed Nitzschia sp., which varied around $0.10-0.15 \mathrm{~min}^{-1}$, across the range of applied temperature (Fig. 7d).

\section{Discussion}

In the present study, we found that both benthic and planktonic diatoms were less inhibited by UVR under moderately increased temperature, while the benthic species was more resistant to UVR under the highest temperature applied, which suggests that the tolerance to environmental stress was associated with the niche environment where the microalgae are living, which would in turn determine the biogeographic properties of the species. These findings imply that temperature is a key factor that mediates the response of diatoms to UVR, while different species have developed distinct mechanisms in response to their particular niche environments (Laviale et al., 2015).

As a basic environmental factor, temperature affects all metabolic pathways, and extreme or sub-optimal conditions are often encountered by various organisms in nature (Mosby and Smith, 2015). The growth response of phytoplankton to temperature varies from species to species but often shows a unimodal pattern (Brown et al., 2004; Chen, 2015). For the applied temperature range in the present study, the growth rate of the benthic species showed a slight response, while growth increased with temperature to a greater extent in the planktonic species, particularly above $25^{\circ} \mathrm{C}$. However, life forms in the natural environment are affected by multiple stressors concomitantly (Boyd et al., 2015). For instance, recent studies have demonstrated that increased temperature would affect phytoplankton interactively with light intensity (Edwards et al., 2016) and could alleviate UV direct inhibition in some sensitive species (Halac et al., 2014). Moreover, in diatoms short-term changes in temperature showed a greater interaction with UV radiation than did long-term exposure, which was particularly important for intertidal benthic species (Sobrino and Neale, 2007). In the present study, when species were acclimated under sub-optimal tem- 
perature $\left(15^{\circ} \mathrm{C}\right)$, both showed obvious sensitivity to UVR (Fig. 1). During the recovery period, however, the effective quantum yield of the benthic diatom could rapidly regain the highest values within 12 min irrespective of the incubation temperature. The planktonic diatom, however, only performed better under short-term elevated temperature. This suggests that the benthic species could have broader adaptability to cope with the highly varied temperature environment they frequently experience (Laviale et al., 2015).

The operation of PSII is sensitive to light intensity as well as quality. High levels of PAR and UVR can usually induce significant damage to this complex, while the de novo synthesis of protein can replace the damaged subunit (Aro et al., 1993; Lavaud et al., 2016). The damage rate $(k)$, which represents the efficiency of detrimental effects, showed a different response for the two species in this study; in the planktonic species, $k$ was sensitive to temperature change, with the lowest value at the medium temperature, but it was quite stable in the benthic species at all temperatures tested. This could be attributed to a decrease in electron transport, or intrinsic differences between benthic and planktonic species (Melis, 1999; Nitta et al., 2005), since $k$ of the planktonic Thalassiosira sp. also showed sensitivity to temperature change (Sobrino and Neale, 2007). The repair rates $(r)$ and the ratio of $r$ to $k$ further demonstrated that the planktonic species had a relatively lower optimal temperature in response to UVR, with the highest $r: k$ and lowest $\mathrm{UV}$ inhibition at $25^{\circ} \mathrm{C}$. In contrast, in the benthic species $r$ and $r: k$ increased steadily and reached relatively stable values at the highest temperature, and this coincided with lower UV inhibition, implying that although acclimated in laboratory conditions for weeks, this species still had an active mechanism to respond to high temperature and UVR, as might occur in its natural niche environment (Laviale et al., 2015).

In addition to repair processes that are initiated after damage, UV-absorbing compounds could directly screen out part of the detrimental radiation, protecting cellular organelles from UV damage (Garcia-Pichel and Castenholz, 1993). In diatoms, however, the spectra of methanol extracts showed only a small absorbance peak in the UVR. Unlike xanthophyll-cycle-related pigments, UV-absorbing compounds (UVACs) are inducible and only synthesized under long-term UV exposure, indicating that UVACs are not a major protecting mechanism for laboratory-cultured diatoms (Helbling et al., 1996). However, the xanthophyll cycle could respond quickly under photo-inhibitory conditions and has been shown to be a major mechanism in diatoms in response to high light or UV (Cartaxana et al., 2013; Zudaire and Roy, 2001). Therefore, the relatively higher absorption in the blue range for benthic species might indicate that temperature enhances the synthesis of xanthophyll-related pigments (Havaux and Tardy, 1996). The differences in absorption spectra of extracted pigments suggest that to better understand the spectral-dependent responses to UV radiation, biological weighting functions should be introduced in this kind of work (Neale et al., 2014).

The temperature-dependent response to UVR has major implications for phytoplankton. With the continuing emission of greenhouse gases, the surface seawater temperature is predicted to increase by up to $4^{\circ} \mathrm{C}$ by the end of this century (New et al., 2011), and this could potentially re-shape the phytoplankton assemblages (Thomas et al., 2012). While the situation might be more complex in the natural environment with the consideration of interaction of UVR with other factors (Beardall et al., 2009), for unicellular green algae, an increase of temperature could mitigate UVR harm for temperate species, while exacerbating UV inhibition for polar species (Wong et al., 2015). Moreover, the tolerance of phytoplankton to extreme temperature would be latitudedependent; for tropical areas where the temperature is already high, an increase of temperature reduced the richness of phytoplankton (Thomas et al., 2012).

The present study showed a differential response to UV radiation for two diatoms from contrasting niches. As predicted, the benthic species had a higher tolerance to the combination of extreme temperature and UV radiation, which can be attributed to the environment in which were living. Below the optimal temperature, both species performed better in response to UV radiation under elevated temperature, suggesting that the natural variation of temperature due to changes in the heat flux from the sun or meteorological events would alter the extent of UV effects on primary producers, and therefore the aquatic ecosystem (Häder et al., 2011). Furthermore, considering the projected global warming scenarios, UV radiation could impose different impacts on phytoplankton with respect to the regional differences (Beardall et al., 2009; Xie et al., 2010).

Data availability. Data in the present study are available at https://doi.org/10.1594/PANGAEA.882597 (Wu et al., 2017).

\section{The Supplement related to this article is available online at https://doi.org/10.5194/bg-14-5029-2017-supplement.}

Competing interests. The authors declare that they have no conflict of interest.

Acknowledgements. This study was supported by the National Natural Science Foundation of China (41476097), the Fundamental Research Funds for the Central Universities (2016B12814, 2017B41714), the Priority Academic Program Development of Jiangsu Higher Education Institutions, and Lianyungang 521 Talent Projects. We thank two anonymous reviewers and Patrick Neale for their helpful comments. 
Edited by: Gerhard Herndl

Reviewed by: Patrick Neale and two anonymous referees

\section{References}

Aro, E. M., Virgin, I., and Andersson, B.: Photoinhibition of Photosystem II. Inactivation, protein damage and turnover, BBABioenergetics, 1143, 113-134, https://doi.org/10.1016/00052728(93)90134-2, 1993.

Barnett, A., Meleder, V., Blommaert, L., Lepetit, B., Gaudin, P., Vyverman, W., Sabbe, K., Dupuy, C., and Lavaud, J.: Growth form defines physiological photoprotective capacity in intertidal benthic diatoms, ISME J., 9, 32-45, https://doi.org/10.1038/ismej.2014.105, 2015.

Beardall, J., Sobrino, C., and Stojkovic, S.: Interactions between the impacts of ultraviolet radiation, elevated $\mathrm{CO}_{2}$, and nutrient limitation on marine primary producers, Photoch. Photobio. Sci., 8, 1257-1265, https://doi.org/10.1039/b9pp00034h, 2009.

Boyd, P. W., Lennartz, S. T., Glover, D. M., and Doney, S. C.: Biological ramifications of climate-change-mediated oceanic multi-stressors, Nature Climate Change, 5, 71-79, https://doi.org/10.1038/nclimate2441, 2015.

Brown, J. H., Gillooly, J. F., Allen, A. P., Savage, V. M., and West, G. B.: Toward a metabolic theory of ecology, Ecology, 85, 17711789, https://doi.org/10.1890/03-9000, 2004.

Campbell, D. A. and Tyystjarvi, E.: Parameterization of photosystem II photoinactivation and repair, BBA-Bioenergetics, 1817, 258-265, https://doi.org/10.1016/j.bbabio.2011.04.010, 2012.

Carstensen, J., Klais, R., and Cloern, J. E.: Phytoplankton blooms in estuarine and coastal waters: Seasonal patterns and key species, Estuar. Coast. Shelf Sci., 162, 98-109, https://doi.org/10.1016/j.ecss.2015.05.005, 2015.

Cartaxana, P., Domingues, N., Cruz, S., Jesus, B., Laviale, M., Serodio, J., and da Silva, J. M.: Photoinhibition in benthic diatom assemblages under light stress, Aquat. Microb. Ecol., 70, 87-92, https://doi.org/10.3354/ame01648, 2013.

Chen, B.: Patterns of thermal limits of phytoplankton, J. Plankton Res., 37, 285-292, https://doi.org/10.1093/plankt/fbv009, 2015.

Edwards, K. F., Thomas, M. K., Klausmeier, C. A., and Litchman, E.: Phytoplankton growth and the interaction of light and temperature: A synthesis at the species and community level, Limnol. Oceanogr., 61, 1232-1244, https://doi.org/10.1002/lno.10282, 2016.

Gao, K., Wu, Y., Li, G., Wu, H., Villafane, V. E., and Helbling, E. W.: Solar UV radiation drives $\mathrm{CO}_{2}$ fixation in marine phytoplankton: A double-edged sword, Plant Physiol., 144, 54-59, https://doi.org/10.1104/pp.107.098491, 2007.

Garcia-Pichel, F. and Castenholz, R. W.: Occurrence of UVAbsorbing, Mycosporine-like compounds among cyanobacterial isolates and an estimate of their screening capacity, Appl. Environ. Microb., 59, 163-169, 1993.

Häder, D.-P., Helbling, E., Williamson, C., and Worrest, R.: Effects of $\mathrm{UV}$ radiation on aquatic ecosystems and interactions with climate change, Photoch. Photobio. Sci., 10, 242-260, 2011.

Halac, S. R., Villafane, V. E., Goncalves, R. J., and Helbling, E. W.: Photochemical responses of three marine phytoplankton species exposed to ultraviolet radiation and increased temperature:
Role of photoprotective mechanisms, J. Photoch. Photobio. B, 141, 217-227, https://doi.org/10.1016/j.jphotobiol.2014.09.022, 2014.

Havaux, M. and Tardy, F.: Temperature-dependent adjustment of the thermal stability of photosystem II in vivo: Possible involvement of xanthophyll-cycle pigments, Planta, 198, 324-333, https://doi.org/10.1007/bf00620047, 1996.

Helbling, E. W., Chalker, B. E., Dunlap, W. C., HolmHansen, O., and Villafane, V. E.: Photoacclimation of Antarctic marine diatoms to solar ultraviolet radiation, J. Exp. Mar. Biol. Ecol., 204, 85-101, https://doi.org/10.1016/0022-0981(96)02591-9, 1996.

Heraud, P. and Beardall, J.: Changes in chlorophyll fluorescence during exposure of Dunaliella tertiolecta to UV radiation indicate a dynamic interaction between damage and repair processes, Photosynth. Res., 63, 123-134, https://doi.org/10.1023/a:1006319802047, 2000.

Irwin, A. J., Nelles, A. M., and Finkel, Z. V.: Phytoplankton niches estimated from field data, Limnol. Oceanogr., 57, 787-797, https://doi.org/10.4319/lo.2012.57.3.0787, 2012.

Keithan, E. D., Lowe, R. L., and DeYoe, H. R.: Benthic diatom distribution in a pennsylvania stream: role of $\mathrm{pH}$ and nutrients, $\mathrm{J}$. Phycol., 24, 581-585, 1988.

Lavaud, J., Strzepek, R. F., and Kroth, P. G.: Photoprotection capacity differs among diatoms: Possible consequences on the spatial distribution of diatoms related to fluctuations in the underwater light climate, Limnol. Oceanogr., 52, 1188-1194, 2007.

Lavaud, J., Six, C., and Campbell, D. A.: Photosystem II repair in marine diatoms with contrasting photophysiologies, Photosynth. Res., 127, 189-199, https://doi.org/10.1007/s11120-015-0172-3, 2016.

Laviale, M., Barnett, A., Ezequiel, J., Lepetit, B., Frankenbach, S., Meleder, V., Serodio, J., and Lavaud, J.: Response of intertidal benthic microalgal biofilms to a coupled light-temperature stress: evidence for latitudinal adaptation along the Atlantic coast of Southern Europe, Environ. Microbiol., 17, 3662-3677, https://doi.org/10.1111/1462-2920.12728, 2015.

Lavoie, M., Raven, J. A., and Levasseur, M.: Energy cost and putative benefits of cellular mechanisms modulating buoyancy in a flagellate marine phytoplankton, J. Phycol., 52, 239-251, https://doi.org/10.1111/jpy.12390, 2016.

Levasseur, M., Therriault, J.-C., and Legendre, L.: Hierarchical control of phytoplankton succession by physical factors, Mar. Ecol.Prog. Ser., 19, 211-222, 1984.

Melis, A.: Photosystem-II damage and repair cycle in chloroplasts: what modulates the rate of photodamage in vivo?, Trend. Plant Sci., 4, 130-135, https://doi.org/10.1016/s1360-1385(99)013874, 1999.

Morel, F. M. M., Rueter, J. G., Anderson, D. M., and Guillard, R. R. L.: Aquil: a chemically defined phytoplankton culture medium for trace metal studies, J. Phycol., 15, 135-141, https://doi.org/10.1111/j.1529-8817.1979.tb02976.x, 1979.

Mosby, A. F. and Smith Jr., W. O.: Phytoplankton growth rates in the Ross Sea, Antarctica, Aquat. Microb. Ecol., 74, 157-171, https://doi.org/10.3354/ame01733, 2015.

Neale, P. J., Pritchard, A. L., and Ihnacik, R.: UV effects on the primary productivity of picophytoplankton: biological weighting functions and exposure response curves of Synechococcus, Biogeosciences, 11, 2883-2895, https://doi.org/10.5194/bg-112883-2014, 2014. 
New, M., Liverman, D., Schroeder, H., and Anderson, K.: Four degrees and beyond: the potential for a global temperature increase of four degrees and its implications, Philos. T. R. Soc. A, 369, 1112-1112, https://doi.org/10.1098/rsta.2010.0351, 2011.

Nitta, K., Suzuki, N., Honma, D., Kaneko, Y., and Nakamoto, H.: Ultrastructural stability under high temperature or intensive light stress conferred by a small heat shock protein in cyanobacteria, FEBS Lett., 579, 1235-1242, https://doi.org/10.1016/j.febslet.2004.12.095, 2005.

Round, F. E., Crawford, R. M., and Mann, D. G.: Diatoms: Biology and Morphology of the Genera, Cambridge University Press, 1990.

Sobrino, C. and Neale, P. J.: Short-term and long-term effects of temperature on photosynthesis in the diatom Thalassiosira pseudonana under UVR exposures, J. Phycol., 43, 426-436, https://doi.org/10.1111/j.1529-8817.2007.00344.x, 2007.

Souffreau, C., Vanormelingen, P., Verleyen, E., Sabbe, K., and Vyverman, W.: Tolerance of benthic diatoms from temperate aquatic and terrestrial habitats to experimental desiccation and temperature stress, Phycologia, 49, 309-324, https://doi.org/10.2216/09-30.1, 2010.

Stevenson, R. J.: Effects of current and conditions simulating autogenically changing microhabitats on benthic diatom immigration, Ecology, 64, 1514-1524, https://doi.org/10.2307/1937506, 1983.

Tedetti, M. and Sempere, R.: Penetration of ultraviolet radiation in the marine environment, A review, Photochem. Photobiol., 82, 389-397, https://doi.org/10.1562/2005-11-09-ir-733, 2006.

Thomas, M. K., Kremer, C. T., Klausmeier, C. A., and Litchman, E.: A global pattern of thermal adaptation in marine phytoplankton, Science, 338, 1085-1088, https://doi.org/10.1126/science.1224836, 2012.

Villareal, T. A.: Positive buoyancy in the oceanic diatom Rhizosolenia debyana $\mathrm{H}$. Peragallo, Deep-Sea Res. Pt. I, 35, 1037-1045, https://doi.org/10.1016/0198-0149(88)90075-1, 1988.
Weisse, T., Groeschl, B., and Bergkemper, V.: Phytoplankton response to short-term temperature and nutrient changes, Limnologica, 59, 78-89, https://doi.org/10.1016/j.limno.2016.05.002, 2016.

Williamson, C. E., Zepp, R. G., Lucas, R. M., Madronich, S., Austin, A. T., Ballare, C. L., Norval, M., Sulzberger, B., Bais, A. F., McKenzie, R. L., Robinson, S. A., Haeder, D.P., Paul, N. D., and Bornman, J. F.: Solar ultraviolet radiation in a changing climate, Nature Climate Change, 4, 434-441, https://doi.org/10.1038/nclimate2225, 2014.

Wong, C.-Y., Teoh, M.-L., Phang, S.-M., Lim, P.-E., and Beardall, J.: Interactive effects of temperature and UV radiation on photosynthesis of Chlorella strains from polar, temperate and tropical environments: Differential impacts on damage and repair, PlosOne, 10, e0139469, https://doi.org/10.1371/journal.pone.0139469, 2015.

Wu, Y., Gao, K., Li, G., and Walter Helbling, E.: Seasonal impacts of solar UV radiation on photosynthesis of phytoplankton assemblages in the coastal waters of the South China Sea, Photochem. Photobiol., 86, 586-592, https://doi.org/10.1111/j.17511097.2009.00694.x, 2010.

Wu, Y., Yue, F., Xu, J., and Beardall, J.: Differential photosynthetic responses of marine planktonic and benthic diatoms to ultraviolet radiation under various temperature regimes, PANGAEA, https://doi.org/10.1594/PANGAEA.882597, 2017.

Xie, S.-P., Deser, C., Vecchi, G. A., Ma, J., Teng, H., and Wittenberg, A. T.: Global warming pattern formation: Sea surface temperature and rainfall, J. Climate, 23, 966-986, https://doi.org/10.1175/2009jcli3329.1, 2010.

Zudaire, L. and Roy, S.: Photoprotection and long-term acclimation to UV radiation in the marine diatom Thalassiosira weissfogii, J. Photoch. Photobio. B, 62, 26-34, https://doi.org/10.1016/s10111344(01)00150-6, 2001. 